\title{
Food insecurity
}

in Mali

\section{Identifying vulnerable} households with precision

Ibrahima BOCOUM

In 2010, $16 \%$ of people in developing countries were undernourished; way above the $10 \%$ target set by the Millennium Development Goals. This poor result calls into question food security policies, which are often based on macroeconomic indicators.

Using household surveys, a research study on Mali confirms that poverty is an important factor of hunger, but it also highlights certain paradoxes: poor households may have enough food, while those that are above the poverty line may not. It explains these paradoxes by identifying other factors influencing the food situation, such as household size, budget constraints, food preferences, and social obligations.

Taking these additional factors into account helps to more accurately characterise undernourished populations and to better target action.

perspəctive

Through Perspective CIRAD provides the opportunity to explore new avenues for discussion and action based on research and expertise, without presenting an institutional position.
In 2010, according to FAO, 925 million people were undernourished, and $98 \%$ of these people lived in developing countries $(16 \%$ of the population of these countries). The Millennium Development Goal - reducing the proportion of people suffering from hunger from $20 \%$ in 1990 to $10 \%$ in 2015 - is far from being achieved. This poor result raises questions about the effectiveness of food security policies.

To estimate the number of undernourished people, policies use macroeconomic data, essentially regarding the availability of food. National food balance sheets are used to assess the agricultural production available for human consumption, an approximation of food consumption (national agricultural pro- duction + imports - exports - stocks - animal feed - seed - biofuels - losses).

FAO converts the available per capita production into calories, compares this to average calorie requirements - which take into account population structure - and thereby calculates the number of undernourished people. These estimates give an aggregate vision of the food situation of a country and can be used to make international comparisons. But they are not detailed enough to accurately identify the target people or groups and to conduct effective food security policies.

However, alongside national macroeconomic statistics, most West African countries have data on the living conditions of households, 
Socio-economic data

on households are

rarely used to assess

the food situation. and even on those of individuals, which are collected with varying degrees of regularity (5 to 10 years). For example, household budget surveys often include a section on food consumption and child nutrition, or even on individuals' perceptions of their situation (LSMS - Living Standards Measurement Study). Demographic and health surveys include anthropometric data. Surveys financed by international organisations (WFP, UNICEF) or NGOs focus on food security and population vulnerability.

Socio-economic data on households are rarely used to assess the food situation. For example, the Malian Poverty Evaluation Survey (Enquête malienne d'évaluation de la pauvreté, EMEP) has only been used to define the poverty line, whereas it provides data on food consumption and household budgets.

\section{The applied method}

The EMEP 2001 provides comprehensive information for a sample of 5000 households, representative of the different regions of Mali, from both rural and urban areas. These households were visited over the course of a week on four occasions in 2001. The information collected concerns: household characteristics and spending; the weight of the food products used in every meal; and the number of people at every meal.

The research study on Mali processed the raw data from this survey.

- The missing or outlying data were identified and corrected by imputation.

- Total spending was used as an approximation of income.

- The value of food for own consumption was estimated and added to spending.

- The number of calories per day and per person was chosen as an indicator of food consumption (the weight of food products used in the composition of a meal was converted into calories). This indicator clearly does not reflect all aspects of food, especially the balance of diets and the quality of micronutrients. It was chosen because it is used as a criterion by the international organisations. Furthermore, compared with calorie requirements, it can be used to qualify the food situation of the individuals in each household.

- Calorie requirements were calculated for the individuals in each household according to gender, age, weight, height and activity level, based on the method set out by Swindale and Ohri-Vachaspati (2005).

- The number of calories consumed outside the home was calculated by dividing the food spending outside the home by the average cost of calories outside the home. This cost was estimated as double that of calories consumed at home, according to results obtained recently in Burkina Faso (E. Becquey, 2010. La sécurité alimentaire des ménages urbains au Burkina Faso. Caractéristiques et mesure. Doctoral thesis. Université Pierre et Marie Curie).

- The income poverty line was determined with the cost of basic needs method. This method is used to calculate the cost of a basket of foodstuffs consumed to a significant extent in all the regions of the country. From this cost are deducted the total costs needed to cover calorie requirements: we thus obtain the food poverty line. To approach the monetary poverty line, households are identified whose food spending is close to the food poverty line, and an average of their total spending is calculated. Although imperfect, this method is considered to be more precise than others.

\section{Hunger is linked to poverty...}

A research study on Mali was based on the EMEP 2001 data. By linking data on food consumption to household characteristics (see the applied method below), it has produced results that confirm the impact of income on food insecurity, along with other more paradoxical findings.

The first finding is that average per capita calorie intake was estimated at $2298 \mathrm{kcal}$ in urban areas and $2245 \mathrm{kcal}$ in rural areas. The average hunger line was evaluated at $2249 \mathrm{kcal}$ in urban areas and $2467 \mathrm{kcal}$ in rural areas (taking into account the intense activity during sowing and harvesting). This shows that around $66 \%$ of the rural population and $51 \%$ of the urban population are calorie deficient.

Another finding is that calorie intake does depend on the evolution of total spending. It increases rapidly when total spending increases, then tends to stabilise (diagram 1). For the median value of total per capita spending (143 euros in rural areas and 232 euros in urban areas), a level of total spending $10 \%$ higher corresponds to a calorie intake $4.5 \%$ higher in rural areas and $2.2 \%$ higher in urban areas. From 294 euros per person per year, calorie intake stagnates, as the people are able to meet their needs.

\section{... and also to other factors}

Income poverty is therefore a major cause of undernourishment in both rural and urban areas. But it is not the only one. Paradoxical situations have been observed (diagram 2). For example, $14 \%$ of the rural households identified as poor (section 3) consume the calories needed to maintain good health and normal physical activity. On the contrary, $18 \%$ of rural households whose total sending is above the poverty line (section 4) are calorie deficient. For urban households, the percentages are respectively $25 \%$ and $15 \%$.

These results confirm the diversity of behaviours and characteristics of households in terms of their food consumption and their income poverty (A. Sen, 1992).

A considerable percentage of calorie-deficient households (around 18\% in rural areas and 
1. Calorie intake rises rapidly with the increase in total spending, then stagnates. Source : Bocoum, 2011

The vertical lines represent total median spending per capita: the blue line in rural areas; the red line in urban areas.

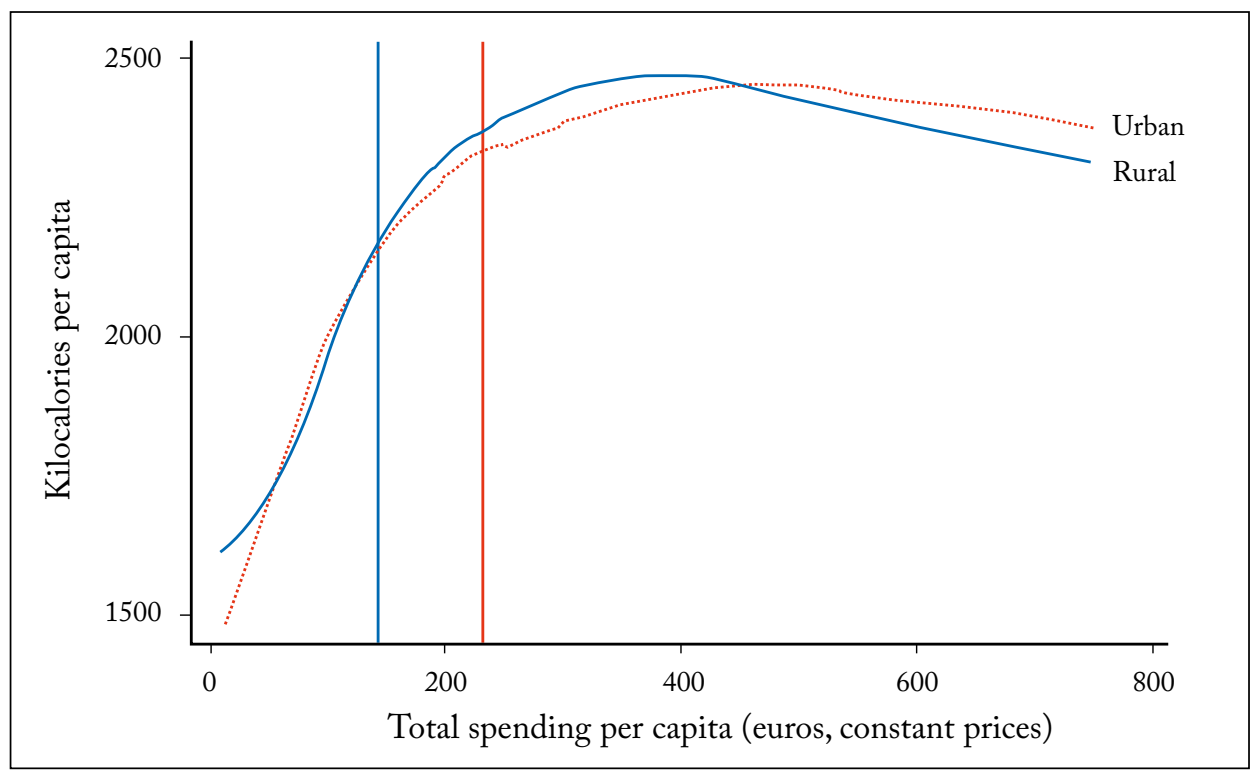

Household size influences food consumption.

2. Poverty is only one factor of undernourishment (here, in rural areas). Source : Bocoum, 2011

The vertical line indicates the income poverty line; the horizontal line, the threshold for covering calorie requirements. second is that "the poor man's share" for unexpected visitors is of more benefit to smaller households if there is no visitor.

Household size also partly explains the paradoxes mentioned, since "better-off" caloriedeficient households are generally large ones.

These paradoxes can be explained by other factors such as budget constraints, food preferences, and social obligations.

The structure of total spending influences food consumption. If health or transport spending increases, the probability of a calorie deficit grows, even for households that are above the poverty line.

Another explanatory factor is food diversification. The wealthiest $20 \%$ of urban households buy less cereal (27.4\% of their food budget) than the poorest $20 \%$ (38.5\%). However, they buy more meat and poultry than the poorest that large households include more children, whose calorie requirements are lower. The

Kilocalories / Requirements (per capita)

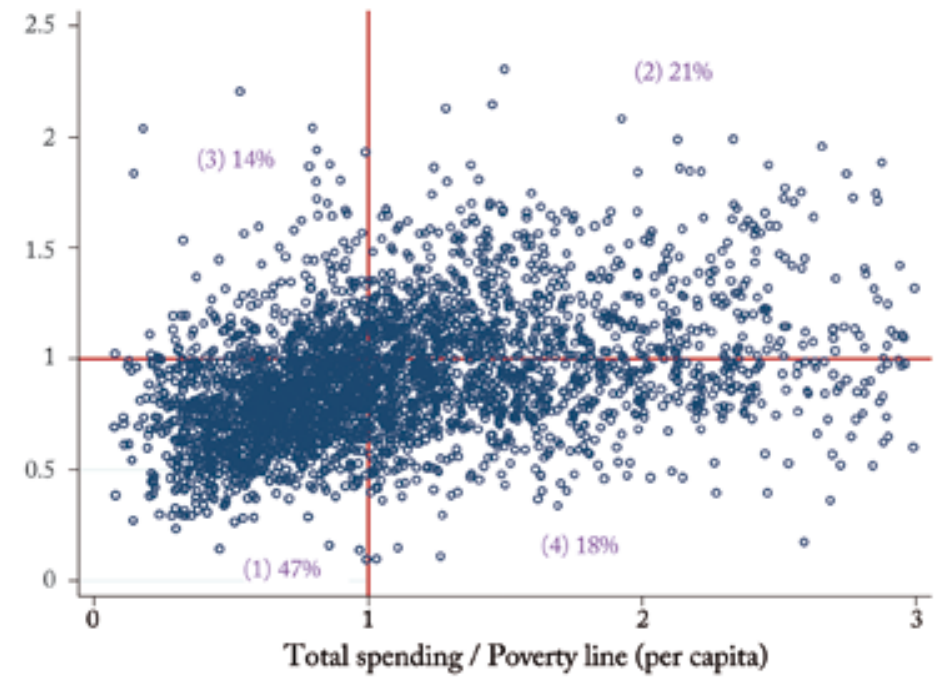


Higher spending

on health and

transport increases

food vulnerability.
(22.5\% compared to $13.4 \%)$. But meat and poultry are less calorific than cereals. These figures explain the paradox of "better-off" calorie-deficient households and of poor households covering their calorie requirements.

Finally, obligations linked to social rank: better-off households, whether in urban or rural areas, receive more guests for meals since their social position implies greater responsibilities.

\section{"Micro" indicators}

Several options exist for proposing usable indicators for food security policies. They supplement other indicators such as the budget share devoted to food, or price levels.

In addition to household size, which is easy to establish, the composition of total spending seems to be a useful indicator for identifying vulnerable households. Indeed, households may be forced to reduce the budget share they allocate to food: temporarily to cope with an

This research was conducted in France and Mali from 2006 to 2009. It received a grant from the French Ministry of Higher Education and Research, and financial support from CIRAD.

\section{A few words about.}

Ibrahima Bocoum is an economics lecturer at the University of Montpellier 3 After his thesis, he worked at CIRAD on the relations between food security and biodiversity until the end of 2011 ibbocoum@gmail.com

\section{cirad}

AGRICULTURAL RESEARCH FOR DEVELOPMENT 42, rue Scheffer 75116 Paris . FRANCE wWW.cirad.fr

perspactive

Editor: Patrick Caron, Deputy Director General of Research and Strategy

Coordination: Corinne Cohen Department for Scientific and Technical Information

Translation: Anna Kiff

Graphic design: Patricia Doucet, Communication Service
During his Master's and $\mathrm{PhD}$ studies from 2005 to 2011 Ibrahima Bocoum was hosted by the MOISA joint research unit (Markets, Organizations, Institutions and Operators' Strategies) and supervised by Sandrine Dury and Johny Egg. For the analysis and processing of consumption data, he was supported by members of the IRD NALIS research unit (Nutrition, Food, Societies). In Mali he received support from several institutions, including: the CSA (Commissariat à la sécurité alimentaire - Food security commission), the DNSI (Direction nationale de la statistique et de l'informatique - National directorate of statistics and informatics), the SAP (Système d'alerte précoce - Early warning

\section{TO FIND OUT MORE}

Banerjee A. V., Duflo E., 2007. The economic lives of the poor. The Journal of Economic Perspectives: A journal of the American Economic Association, 21(1), 141.

Behrman J. R., Deolalikar, A. B., 1987. Will Developing Country Nutrition Improve with Income? A Case Study for Rural South India. The Journal of Political Economy, 95(3), 492. accident or illness; or more permanently, in order to travel, especially in town to get to work. Furthermore, determining the real costs for a household (for example the number of people who share meals in addition to the household members) would mean many households that appear to be "better-off" would in fact be classed as vulnerable.

To go further, it would be interesting to have indicators concerning individuals. Indeed, not all the members of a household have the same access to food. Such indicators could be taken from research on the distribution of resources within households.

Gathering and comparing information scattered between existing surveys, and processing this information based on suggested indicators and others yet to be created, is a simple way to identify with greater accuracy undernourished and vulnerable populations, and thereby better target interventions. FAO is in fact working in this direction: it is beginning to take advantage of household surveys.

system), the ODHD (Observatoire du développement humain durable - sustainable human development monitoring body), the IER (Institut d'études rurales - rural studies institute), for the national institutions; AFRISTAT, WFP (World Food Programme), for the international institutions; and ACF (Action against Hunger) for the NGOs.

The research led to a doctoral thesis cosupervised by Jean-Marie Boisson (Emeritus Professor at Montpellier 1 University) and Javier Herrera (Director of Research at IRD), which was defended in April 2011 in Montpellier: "Sécurité alimentaire et pauvreté. Analyse économique des déterminants de la consommation des ménages. Application au Mali". Doctoral thesis in economics, University of Montpellier 1. The thesis will be available soon at http://umr-moisa.cirad.fr/ en/ (Education and training, Former doctorate students).

Deaton A. S., 1997. The Analysis of Household Surveys: A Microeconometric Approach to Development Policy. Baltimore : Johns Hopkins University Press.

Sen A. K., 1992. Repenser l'inégalité. Paris : Éditions du Seuil.

Swindale A. \& Ohri-Vachaspati P. (ed.), 2005. Measuring household food consumption: a technical guide. Washington DC: Food and Nutrition Technical Assistance Project (FANTA). 